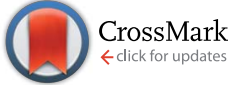

Cite this: J. Mater. Chem. A, 2015, 3 , 7822

Received 6th January 2015

Accepted 2nd March 2015

DOI: 10.1039/c5ta00117j

www.rsc.org/MaterialsA

\section{Metal oxide arrays from block copolymer thin film templates $\dagger$}

\begin{abstract}
Michael K. Mayeda, ${ }^{a}$ Jeffery Hayat, ${ }^{\text {b }}$ Thomas H. Epps, III ${ }^{\star a}$ and Jochen Lauterbach ${ }^{\star c}$
We present a simple, though uncommonly used, method to produce versatile, well-ordered, nanoscale arrays of metal oxides such as $\mathrm{MgO}, \mathrm{Al}_{2} \mathrm{O}_{3}, \mathrm{TiO}_{2}, \mathrm{MnO}_{2}, \mathrm{Fe}_{2} \mathrm{O}_{3}, \mathrm{CO}_{3} \mathrm{O}_{4}, \mathrm{NiO}, \mathrm{CuO}, \mathrm{ZnO}, \mathrm{ZrO}_{2}, \mathrm{RuO}_{2}$, $\mathrm{SnO}_{2}$, or $\mathrm{Ce}_{2} \mathrm{O}_{3}$ by decoupling metal oxide precursor incorporation from block copolymer (BCP) template formation. In this work, neat BCP thin films were cast and annealed, using standard techniques, to generate templates. The templates were immersed in a precursor solution and formed metalpolymer complexes in one polymer domain. Finally, the organics were removed in an oxidative environment to leave the templated metal oxides. As a concrete example of the method's applicability, we show that the templating method produced ordered $\mathrm{TiO}_{2}$ arrays that exhibited a $13 \%$ increase in photocatalytic activity over $\mathrm{TiO}_{2}$ produced by EISA. Furthermore, the addition of gold nanoparticles further improved photocatalytic activity by $43 \%$ on our templated $\mathrm{TiO}_{2}$, whereas gold nanoparticles on EISA $\mathrm{TiO}_{2}$ exhibited no improvement. The simplicity and modularity of the templating method makes it amenable to additional applications in catalysis, optics, and sensors.
\end{abstract}

\section{Introduction}

The development of Mobil's zeolites in the 1960s sparked an avalanche of research on the design of structured materials with nanometer-scale features $(>1 \mathrm{~nm})$ for applications in catalysis and separations. ${ }^{1}$ Innovative uses of structure directing agents can yield nanomaterials with improved catalytic activity. Whereas small-molecule surfactants have proven to be excellent subnanometer structure directing agents, ${ }^{2}$ block copolymers (BCPs) offer a macromolecular analog with tunable molecular weights, block choices, and compositions., ${ }^{3,4}$ When implemented in thin film environments ( $<100 \mathrm{~nm}$ in thickness), BCPs can serve as ideal organic templates, whose nanostructure can be controlled through processing techniques..$^{5-10}$ These films can be used to direct the nanoscale structure of inorganic materials for catalysts, sensors, and optics applications. ${ }^{\mathbf{1 1}}$ Improved ordering of the thin film morphology, to $\sim \mathrm{cm}^{2}$ grain sizes, is important for applications in competition (or in concert) with lithography and could be achieved by

\footnotetext{
${ }^{a}$ Department of Chemical \& Biomolecular Engineering, University of Delaware, Newark, DE 19716, USA. E-mail: thepps@udel.edu; Fax: +1 302831 1048; Tel: +1 3028310215

${ }^{b}$ Department of Chemistry \& Biochemistry, University of South Carolina, Columbia, SC 29201, USA

'Department of Chemical Engineering, University of South Carolina, Columbia, SC 29201, USA. E-mail: lauteraj@cec.sc.edu; Fax: +1 803777 8292; Tel: +1 8037777904 $\uparrow$ Electronic supplementary information (ESI) available: AFM images of MgO, $\mathrm{Al}_{2} \mathrm{O}_{3}, \mathrm{MnO}_{2}, \mathrm{Co}_{3} \mathrm{O}_{4}, \mathrm{NiO}, \mathrm{CuO}, \mathrm{ZnO}, \mathrm{ZrO}_{2}, \mathrm{RuO}_{2}, \mathrm{SnO}_{2}$, and $\mathrm{Ce}_{2} \mathrm{O}_{3}$ arrays; XPS peak positions of template oxides; titania loading calculations; time lapse UV-vis spectra of methylene blue photodegradation using SPICE $\mathrm{TiO}_{2}$; and $\mathrm{TiO}_{2}$ dispersion calculations. See DOI: 10.1039/c5ta00117j
}

implementing complementary techniques that employ topographical patterning or external fields..$^{\mathbf{8 1 2 - 1 6}}$

BCP templated metal oxide arrays facilitate a variety of exciting applications in magnetic bit patterned media, seedmediated nanotube growth, energy harvesting, and heterogeneous catalysis. ${ }^{17-22}$ The vast majority of previous investigations involving BCP templating follow two routes: (1) segregating preformed nanoparticles or (2) using in situ sol-gel methods. The former approach benefits from advances in nanoparticle synthesis, which allows researchers to tune particle size, shape, crystallinity, and composition. ${ }^{23}$ Additionally, templating preformed nanoparticles is a convenient route to ensure that the inorganic material retains the desired properties of interest. Previous work by Epps and coworkers templated pre-synthesized gold nanoparticles in poly(styrene- $b$-isoprene- $b$-styrene) thin films by tuning the particles' surface energies using ligand exchanges. ${ }^{24}$ Kramer and coworkers also have investigated gold nanoparticle segregation in poly(styrene- $b$ - 2 vinylpyridine) (PS$b$-P2VP) BCPs by manipulating ligand chemistry, density, and molecular weight. ${ }^{25-28}$ Several reviews succinctly describe efforts to incorporate particles with varying composition, size, and shape into BCPs. ${ }^{29-32}$ In all cases, preformed nanoparticle miscibility and templating generally were dominated by the particle-polymer entropic (particle size and shape) and enthalpic (ligand chemistry) interactions.

In situ sol-gel methods use a sacrificial BCP to arrange metal salt precursors into nanoscale features and subsequently reduce, oxidize, or calcine the composite to simultaneously form the templated material and remove the polymer. ${ }^{33,34}$ This versatile method can be used to create many types of industrially 
relevant crystals, powders, and films. Within sol-gel techniques, evaporation induced self-assembly (EISA) is a popular method for templating inorganic materials. ${ }^{2}$ In short, the polymer and metal precursor are combined in a single solution and a thin film is coated onto a substrate. The evaporation of solvent creates a concentration gradient that acts as an ordering front that produces the nanoscale features. Features can be tuned by adjusting the polymer molecular weight, ${ }^{35}$ sol-gel concentration, ${ }^{33,36,37}$ and coating procedure. ${ }^{38}$ Researchers have used the EISA-templating method to produce arrays of gold, cobalt, and cobalt oxide, but ordering remains poor (grain size $<1 \mu \mathrm{m}^{2}$ ). ${ }^{39-43}$ Poor ordering likely was due to polymer/metal inter- and intramolecular interactions that inhibit polymer chain mobility and prevent BCP ordering. ${ }^{44}$ To maximize BCP chain mobility, Boyen and coworkers modified the EISA method by complexing Fe and $\mathrm{Nb}$ salts with homopolymer P2VP (h2PVP) prior to blending with the PS- $b$-P2VP solution. ${ }^{45}$ Thin films of salt/h2VP/PS- $b$-P2VP produced well-ordered arrays with $\approx 1 \mu \mathrm{m}^{2}$ grain sizes. However, this modification to the traditional EISA method was limited to metal loading ratios of $\mathrm{mol}_{\text {metal }}: \operatorname{mol}_{2 \mathrm{VP} \text {-monomer }} \leq 0.2$ to avoid macrophase separation. On the other hand, Russell and co-workers employed a preformed BCP template to create wellordered $\mathrm{Au} / \mathrm{Ag}$ arrays for surface plasmon resonance studies. ${ }^{\mathbf{4 6}}$ Morris and coworkers have used the method to produce metal oxides with superparamagnetic and ferroelectric properties. ${ }^{47-49}$ Although the method was proven, ${ }^{\mathbf{5 0}}$ researchers have yet to use it for catalysis applications.

We use the preformed BCP template method, hereafter referred to as spincoat-pattern-immerse-complex-etch (SPICE) to produce thin films of well-ordered arrays that were otherwise difficult to achieve via the EISA/dip-coating approach. We build upon previous investigations ${ }^{\mathbf{4 6 5 0}}$ by creating well-ordered hexagonally packed arrays of $\mathrm{MgO}, \mathrm{Al}_{2} \mathrm{O}_{3}, \mathrm{TiO}_{2}, \mathrm{MnO}_{2}, \mathrm{Fe}_{2} \mathrm{O}_{3}$, $\mathrm{Co}_{3} \mathrm{O}_{4}, \mathrm{NiO}, \mathrm{CuO}, \mathrm{ZnO}, \mathrm{ZrO}_{2}, \mathrm{RuO}_{2}, \mathrm{SnO}_{2}$, and $\mathrm{Ce}_{2} \mathrm{O}_{3}$. Furthermore, we demonstrate an improvement in photocatalytic activity of SPICE $\mathrm{TiO}_{2}$ and $\mathrm{Au} / \mathrm{TiO}_{2}$ over EISA TiO${ }_{2}$. In addition to photocatalysis, we anticipate this method will be critical to developing advanced materials for sensors, environmental catalysis, and lithography applications.

\section{Experimental}

\section{Materials}

All materials were used as received. Poly(styrene- $b$-ethylene oxide) $\left(\right.$ PS- $b$-PEO; $D=1.04, \bar{M}_{\mathrm{N} \text {,styrene }}=16 \mathrm{~kg} \mathrm{~mol}^{-1}, \bar{M}_{\mathrm{N} \text {,ethylene oxide }}=5$ $\mathrm{kg} \mathrm{mol}{ }^{-1}$ ) was purchased from Polymer Source, Inc. Iron(III) nitrate nonahydrate (ACS reagent) was purchased from Sigma-Aldrich. Titanium(Iv) tetraisopropoxide (98+\%) and poly(acrylic acid) (25 wt $\%$ aqueous solution, $\bar{M}_{\mathrm{W}}=240 \mathrm{~kg} \mathrm{~mol}^{-1}$ ) were purchased from Acros Organics. Aluminum(III) nitrate nonahydrate (98\%), cerium(III) nitrate hexahydrate (REacton ${ }^{\circledR}, 99.5 \%$ ), cobalt(II) nitrate hexahydrate (ACS reagent), copper(II) nitrate hemipentahydrate (98\%), magnesium(II) nitrate hexahydrate (98\%), manganese(II) nitrate hydrate (99.98\%), nickel(II) nitrate hexahydrate (98\%), tin(II) chloride dihydrate (ACS reagent), zinc(II) nitrate hydrate (99\%), zirconium(Iv) dichloride oxide octahydrate (98\%), and methylene blue (MB) (high purity biological stain) were purchased from Alfa Aesar. ACS grade toluene, tetrahydrofuran, ethanol, and 2-propanol were purchased from BDH. Deionized water was obtained from a Millipore Milli-Q Direct 8 system. Hydrochloric acid (37\% in water, technical) was purchased from Fisher Scientific. Silicon and silicon oxide (500 $\mathrm{nm}$ on silicon) wafers were purchased from Wafer World. Both types of wafers were rinsed with toluene, dried with a nitrogen stream, and cleaned in a Jelight Model 42 UVO-cleaner for $30 \mathrm{~min}$ prior to polymer spincoating.

\section{Templating procedure}

The SPICE method is depicted in Scheme 1. Each of the subprocesses are explained in detail; however, it should be noted that sub-processes can be substituted (e.g., thermal annealing instead of solvent vapor annealing, dip-coating instead of spincoating, calcination instead of ozone etching, etc.).

Spincoating films. Films were made using a Laurell WS4006NPP-Lite spincoater. Toluene solutions of PS- $b$-PEO (1 wt $\%$ ) were stirred for $1 \mathrm{~h}$ and subsequently syringe filtered $(0.2 \mu \mathrm{m}$, PTFE) prior to film casting. Approximately $40 \mu \mathrm{L}$ of solution were quickly syringed onto substrates spinning at 3000 RPM for 30 s. Films were further dried under nitrogen. Using a Filmetrics F20 instrument, thicknesses of as-cast films were analyzed on silicon wafers. Further processing (detailed below) was carried out for films deposited on silicon oxide wafers.

Pattern formation. Perpendicularly-oriented hexagonally array patterns of PEO domains in a PS matrix were made by solvent annealing PS- $b$-PEO films with toluene/water in a high humidity chamber. ${ }^{\mathbf{5 1}}$ Films were placed in a bell jar with a beaker of $4 \mathrm{~mL}$ of toluene. The bell jar was positioned within a high humidity chamber. Humidity was controlled by bubbling nitrogen through deionized water that was maintained at $60{ }^{\circ} \mathrm{C}$. After exposure to saturated toluene vapor at room temperature for $18 \mathrm{~h}$, the bell jar was opened to simultaneously allow toluene evaporation and humidity exposure. Films were exposed to the high humidity environment for $15 \mathrm{~min}$ before being removed from the chamber. It should be noted that although arrays of perpendicular PEO domains were achieved by toluene solvent annealing alone, the addition of high humidity $(>90 \% \mathrm{RH})$ increased grain sizes from less than $1 \mu \mathrm{m}^{2}$ to greater than $4 \mu \mathrm{m}^{2}$.

Immersion and metal complexation. Table S1 (ESI $\dagger$ ) details the processing conditions for each metal oxide sample. For $\mathrm{Mg}$, $\mathrm{Al}, \mathrm{Mn}, \mathrm{Fe}, \mathrm{Co}, \mathrm{Ni}, \mathrm{Cu}, \mathrm{Zn}, \mathrm{Sn}, \mathrm{Ru}$, or $\mathrm{Ce}$, a $1.0 \mathrm{M}$ precursor in ethanol solution was prepared. For $\mathrm{Zr}$ solutions, 0.5 M solutions in ethanol/water (equal volume) were mixed to adequately dissolve the precursor. For Ti solutions, $0.25 \mathrm{~g} \mathrm{HCl}$ solution, $0.7 \mathrm{~g}$ titanium tetraisopropoxide, and $5 \mathrm{~mL}$ 2-propanol were stirred for $30 \mathrm{~min}$. All annealed PS- $b$-PEO films were immersed in a precursor solution for $15 \mathrm{~min}$. Immersion allowed the metal ions to selectively complex with the PEO domains. After submerging the BCP film in the precursor solution, excess precursor solution was removed by rinsing with 2-propanol and drying in a nitrogen stream.

EISA TiO $_{2}$. For comparison purposes, a film was made using the EISA method. After stirring, $0.2 \mathrm{~mL}$ of the titania solution was combined with $0.8 \mathrm{~mL}$ of the PS- $b$-PEO toluene solution 

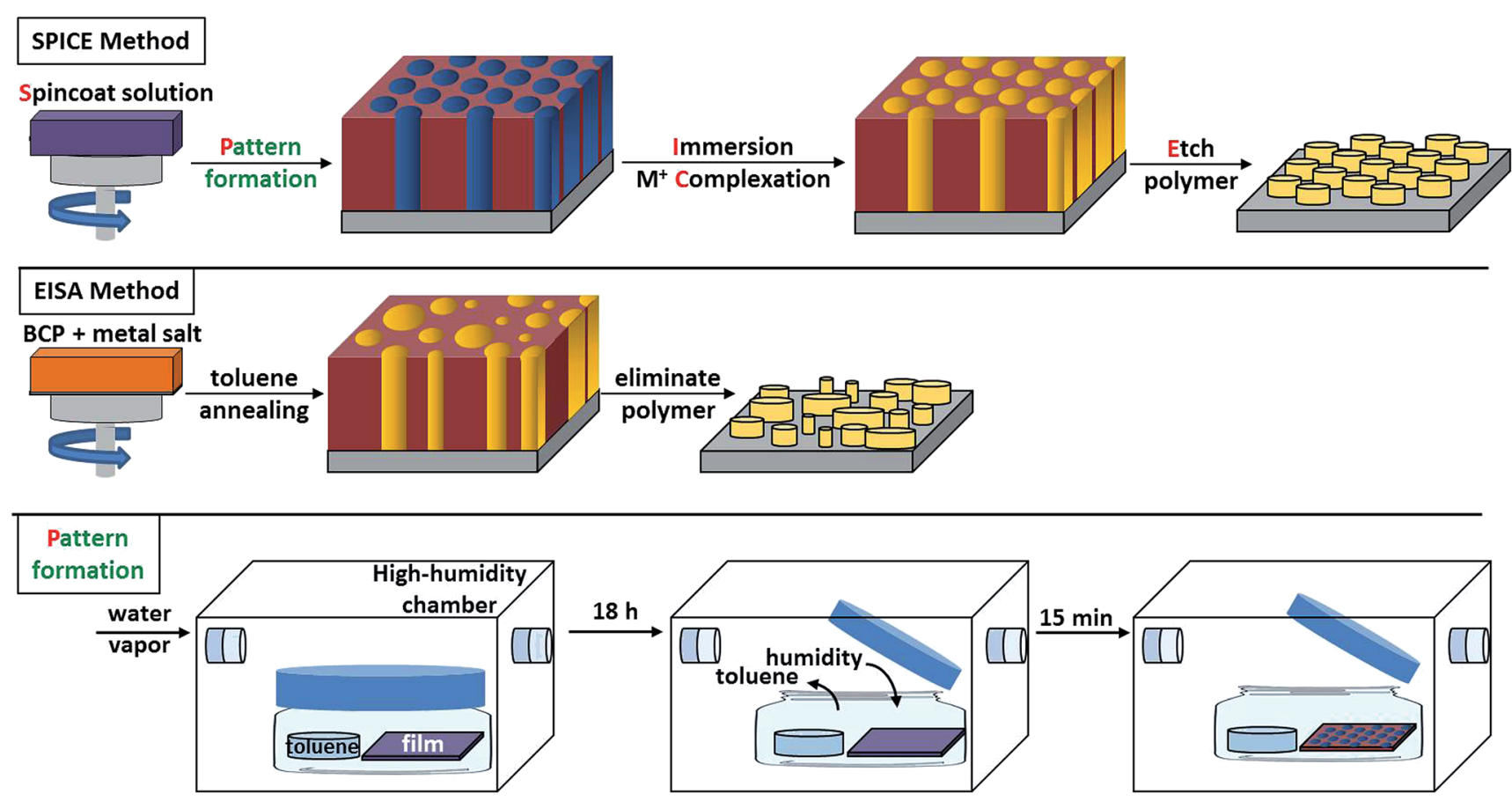

Scheme 1 The spincoat-pattern-immerse-complex-etch (SPICE) templating method decouples polymer annealing from the metal precursor gel incorporation. Traditional methods, represented by EISA, spincoat an all-in-one solution that includes both polymer and metal precursor. Although EISA has fewer steps, it can produce irregular arrays of inorganic material. Pattern formation was achieved by annealing with toluene and water vapor using standard solvent annealing techniques enclosed in a humidified glove box.

( $1 \mathrm{wt} \%$ ), and a film was spincoated as previously described. Cast films were annealed in saturated toluene vapor $(2 \mathrm{~h})$ without water, which would have undesirably hydrolyzed the titanium precursor.

Etching template. For all films, template etching and metal oxidation were simultaneously achieved using a UVO cleaner for 30 min. Residual carbon was removed by rinsing with toluene and drying under a dry nitrogen stream.

Gold nanoparticle addition. To demonstrate additional modularity of SPICE, gold nanoparticles (AuNP) were spincoated onto the SPICE- and EISA-templated $\mathrm{TiO}_{2}$ after polymer removal to enhance the photocatalytic degradation of $\mathrm{MB}$. AuNPs were synthesized according to the Brust-Schiffrin method. ${ }^{52}$ AuNPs $(3.5 \pm 1.0 \mathrm{~nm}$ diameter $)$ were stabilized in toluene solutions with dodecanethiol. ${ }^{24}$

\section{Film characterization}

Atomic force microscopy (AFM) images were recorded with a Bruker Multimode Nanoscope V system. AppNano ACL tips (190 $\mathrm{kHz}$ resonant frequency, $58 \mathrm{~N} \mathrm{~m}^{-1}$ spring constant) were used in tapping mode. Image processing and FFTs of micrographs were performed with ImageJ.

X-ray photoelectron spectroscopy (XPS) measurements were performed on a Kratos Axis Ultra DLD instrument equipped with a monochromated $\mathrm{Al} \mathrm{K} \alpha$ X-ray source and a hemispherical analyzer. All analyzed metal oxide arrays were deposited on silicon oxide wafers. Binding energies were calibrated using $\mathrm{Si}$ $2 \mathrm{p}$ at $103.3 \mathrm{eV}$.
Transmission electron microscopy (TEM) images were taken with a Hitachi H8000 operated at $150 \mathrm{kV}$. PS- $b$-PEO films containing titania precursor were peeled and mounted onto copper mesh grids according to a method previously described in the literature. ${ }^{53}$ The composite film was prepared for peeling by depositing a thin layer of carbon $(<10 \mathrm{~nm})$ using a Hitachi carbon evaporator. A droplet $(<1 \mathrm{~mL})$ of $25 \mathrm{wt} \%$ poly(acrylic acid) (PAA) was drop-cast and allowed to dry overnight at atmospheric conditions. A razor blade was used to remove the resulting solid, which adhered to the polymer composite film. The PAA was dissolved in a large volume of water. The resulting floating films were mounted onto copper mesh grids or silicon nitride membrane window grids and allowed to air dry for at least 15 min before loading into the TEM.

\section{Photocatalysis experiments}

We demonstrate the SPICE method through the improved photocatalytic degradation of $\mathrm{MB}$, which is an industrial pollutant commonly found in textile waste streams. ${ }^{20}$ In this work, an aqueous solution of $1 \times 10^{-5} \mathrm{M}$ MB was stirred for 2 days and then stored in a dark environment for later use. Wafer fragments $\left(\sim 2 \mathrm{~cm}^{2}\right)$ and $3.3 \mathrm{~mL}$ of MB solution were placed in Brandtech cuvettes (220-900 nm transparency). The surface areas of the samples were hard to measure when the wafer fragments were irregularly shaped. Therefore, degradation rates were normalized by the weights of the wafer fragments. Irradiation was accomplished with a ScienceTech SF300A solar simulator coupled with a ScienceTech 500-300 power supply (350 W average output). Wafer fragments were removed from 
the cuvettes prior to UV-vis measurements, which were recorded with a Shimadzu UV2450 instrument. The $665 \mathrm{~nm}$ peak was monitored during time-lapse studies; peak area integrations from 550-740 nm were calculated. Photocatalytic experiments were reproduced three times for each sample.

\section{Results and discussion}

In heterogeneous catalysis, ordered and narrowly disperse features made by bottom-up processes are critical for applications requiring maximum active surface area. Thus, grain size and narrow structural dispersity inherent in BCP films is an important aspect of the SPICE method. In our case, perpendicularly-oriented and hexagonally-packed domains of PEO cylinders in PS- $b$-PEO films (30 nm thick) were obtained by toluene vapor annealing in a high-humidity chamber, as depicted in Scheme $1 .^{51}$

The average radius of the PEO domains in a toluene/water annealed neat polymer film was $8.7 \pm 0.8 \mathrm{~nm}(>2500$ measurements) (Fig. 1b). The inset fast Fourier transform (FFT) exhibits $4^{\text {th }}$ order peaks, which corroborate the excellent order and large grain sizes achieved by high-humidity annealing. Grain sizes of toluene/water vapor annealed PS- $b$-PEO films were greater than $4 \mu \mathrm{m}^{2}$. The PS- $b$-PEO films were used to template SPICE $\mathrm{TiO}_{2}$ (Fig. 1d) and Au on SPICE $\mathrm{TiO}_{2}$ (Fig. 1e) samples. On the other hand, films that were annealed by only toluene or tetrahydrofuran vapor contained grains that were less than $1 \mu \mathrm{m}^{2}$ (Fig. 1a). Additionally, EISA-templated $\mathrm{TiO}_{2}$ exhibited large size distributions and poor order (Fig. 1c). These results highlighted the importance of using high-humidity during the annealing step.

Some metal precursors, such as the titanium alkoxide and tin chloride used in this study, are susceptible to hydrolysis and cannot be processed in humid or aqueous environments. ${ }^{54}$ By separating template formation and metal precursor inclusion into two decoupled steps, the SPICE method can take advantage of annealing techniques (using high humidity in this case) that otherwise would be precluded by the presence of the metal precursor. To further extend this idea, the authors envision bolstering the SPICE method with supplementary annealing techniques that employ external fields, shear fields, or patterned substrates. Achieving wafer-sized areas of templated material is industrially relevant for magnetic storage media and energy harvesting. ${ }^{55,56}$

Metal oxides were templated into the annealed PS- $b$-PEO films by a simple immersion process. BCP films were submerged in a metal precursor solution to allow the metal ions to selectively complex with the ethylene oxide monomer units. A typical loading ratio of 0.38 was achieved, which is almost twice that achieved by Boyen and coworkers (calculations are available in ESI $\dagger$ ). ${ }^{45}$ Metal oxide formation and polymer removal were simultaneously achieved using an ultraviolet ozone (UVO) oven. The versatility of the SPICE procedure was exemplified by templating commonly used metal oxides: $\mathrm{MgO}, \mathrm{Al}_{2} \mathrm{O}_{3}, \mathrm{TiO}_{2}$,
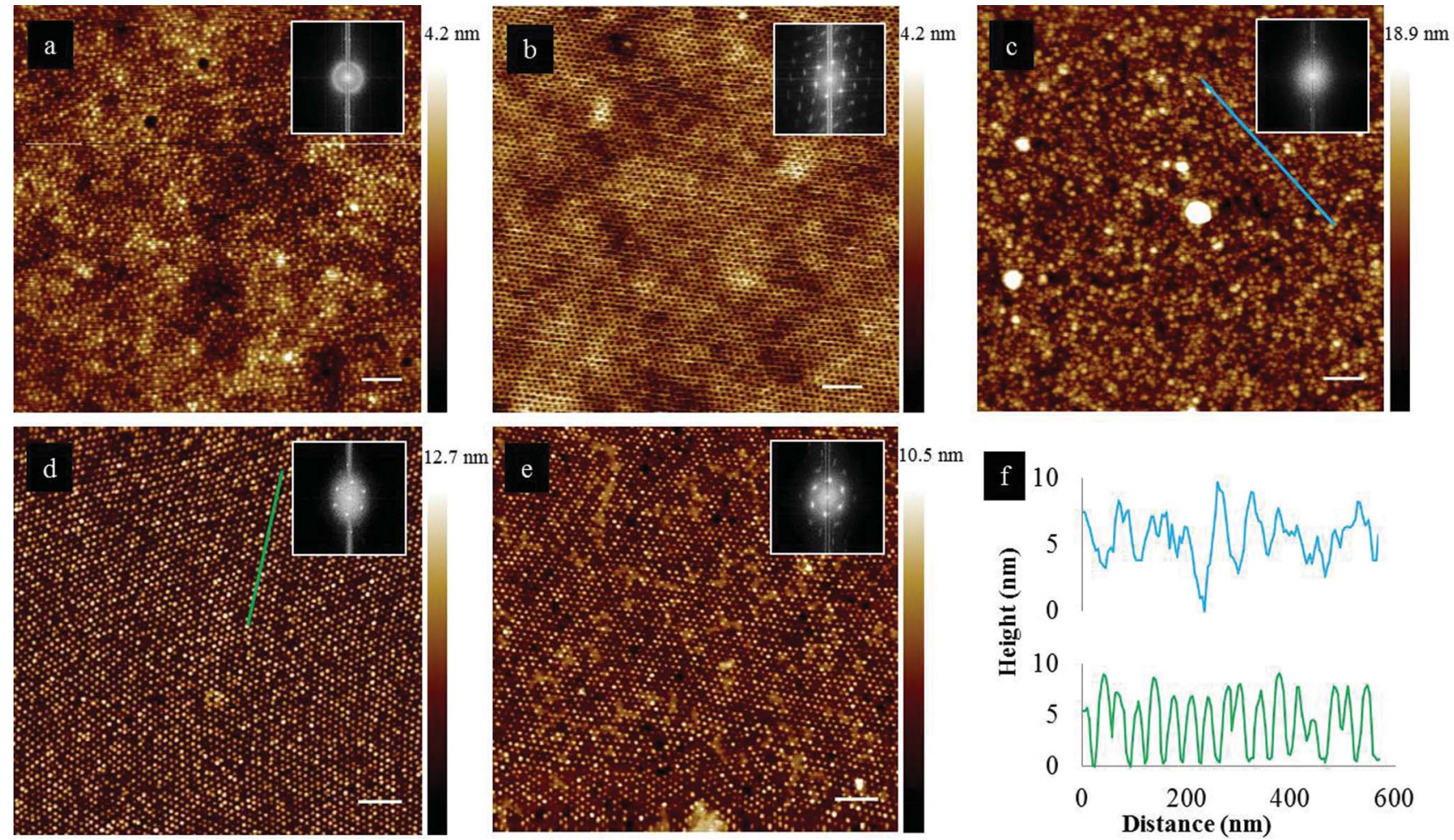

Fig. 1 Atomic force microscopy height images of PS-b-PEO films after solvent vapor annealing with (a) toluene and (b) toluene/water. $\mathrm{TiO}_{2}$ arrays were templated by (c) EISA and (d) SPICE; and (e) AuNPs were spincoated onto templated SPICE TiO, Inset images are FFTs of the AFM images. Scale bars represent $200 \mathrm{~nm}$. (f) Line scans show height profiles of the $\mathrm{TiO}_{2}$ made by the SPICE (green, bottom) and EISA (blue, top) methods. 
$\mathrm{MnO}_{2}, \mathrm{Fe}_{2} \mathrm{O}_{3}, \mathrm{Co}_{3} \mathrm{O}_{4}, \mathrm{NiO}, \mathrm{CuO}, \mathrm{ZnO}, \mathrm{ZrO}_{2}, \mathrm{RuO}_{2}, \mathrm{SnO}_{2}$, and $\mathrm{Ce}_{2} \mathrm{O}_{3}$. Empirical formulas for the metal oxides were determined using high resolution X-ray photoelectron spectroscopy (XPS) scans to identify the oxidation states of the metals. ${ }^{57}$ Fig. 1a-e show AFM images of selected metal oxide arrays as well as corresponding FFTs in the insets. Height images of the remaining metal oxides (Fig. S1 $\dagger$ ) and XPS peak positions of all metal oxides (Table S2 $\dagger$ ) can be found in the ESI. $\dagger$ Hexagonallypacked metal oxide dots are noted in Fig. $1 \mathrm{~b}, \mathrm{~d}$, e, and $\mathrm{S} 1 ; \uparrow$ all corresponding FFTs reveal reflections that are characteristic of hexagonal packing. $2^{\text {nd }}$ order reflections are noted for $\mathrm{Co}_{3} \mathrm{O}_{4}$, $\mathrm{Fe}_{2} \mathrm{O}_{3}, \mathrm{MgO}, \mathrm{MnO}_{2}, \mathrm{ZnO}, \mathrm{SnO}_{2}$, and $\mathrm{TiO}_{2}$ samples. After polymer removal, the height of the templated materials ranged from 1-7 nm. For $\mathrm{TiO}_{2}$, a $30 \mathrm{~nm}$ thick BCP film template produced an average oxide dot height of $5.4 \pm 1.4 \mathrm{~nm}$. The height reduction was attributed to the significant mass loss during polymer template removal and was used to calculate the average oxide loading. The average radius of a templated dot was $8.5 \pm 1.9 \mathrm{~nm}$, which closely matches the initial PEO domain size after solvent annealing $(8.7 \pm 0.8 \mathrm{~nm}) .{ }^{46}$ The similarity in PEO domain size and the SPICE dot size suggests that templated metal oxide size can be controlled by tuning the polymer molecular weight and volume fraction. ${ }^{58}$ Highly ordered PS- $b$-PEO films led to highly ordered metal oxide dots, supporting the efficacy and simplicity of the SPICE templating method.

The EISA-templating method was applied to the same polymer and titania precursor solution for the purpose of comparison. Because the titania precursor was highly sensitive to water, toluene/water solvent vapor undesirably hydrolyzed the titania precursor in the EISA film (Fig. 2a). Thus, only toluene vapor was used to anneal EISA films. Despite, our best efforts to anneal the EISA composite with toluene vapor, the resulting titania were poorly ordered and disperse in diameter (Fig. 2b). On the other hand, the SPICE method allowed the use of highhumidity annealing conditions and produced highly-ordered PEO domains, which preferentially absorbed the titania precursor (Fig. 2c). TEM images illustrate the improvement in order and dispersity of the SPICE method.

The EISA method produced an average $\mathrm{TiO}_{2}$ dot radius of 9.8 $\pm 4.4 \mathrm{~nm}$. Decreased morphology control was evidenced by the line scan in Fig. 1f, AFM image (Fig. 1c), and TEM image (Fig. 2b). Dispersion calculations are available in ESI. $\uparrow$ The FFT of EISA micrographs showed no spots or rings, indicating the absence of any significant ordering. Poor ordering of annealed EISA films was attributed to hydrolytic oligomerization of titania and reduced polymer chain mobility caused by coordination bonds between the titania precursor and PEO domains. ${ }^{37,59}$ Huh and coworkers studied the effect of Cd coordination with poly(4-vinylpyridine) (P4VP) and found that increasing the salt loading increased gelation and decreased ordering of their Cd/PS- $b$-P4VP system. ${ }^{44}$ Similarly, it is expected that PEO-metal complexes hinder polymer chain mobility during solvent vapor annealing. By decoupling the polymerordering from the metal-coordinating, the SPICE method produced narrow size distributions and highly ordered arrays.

It has been established that $\mathrm{Au}$ or $\mathrm{Ag}$ nanoparticles can be used to improve the photocatalytic efficiency of $\mathrm{TiO}_{2} \cdot{ }^{60-62}$ As a
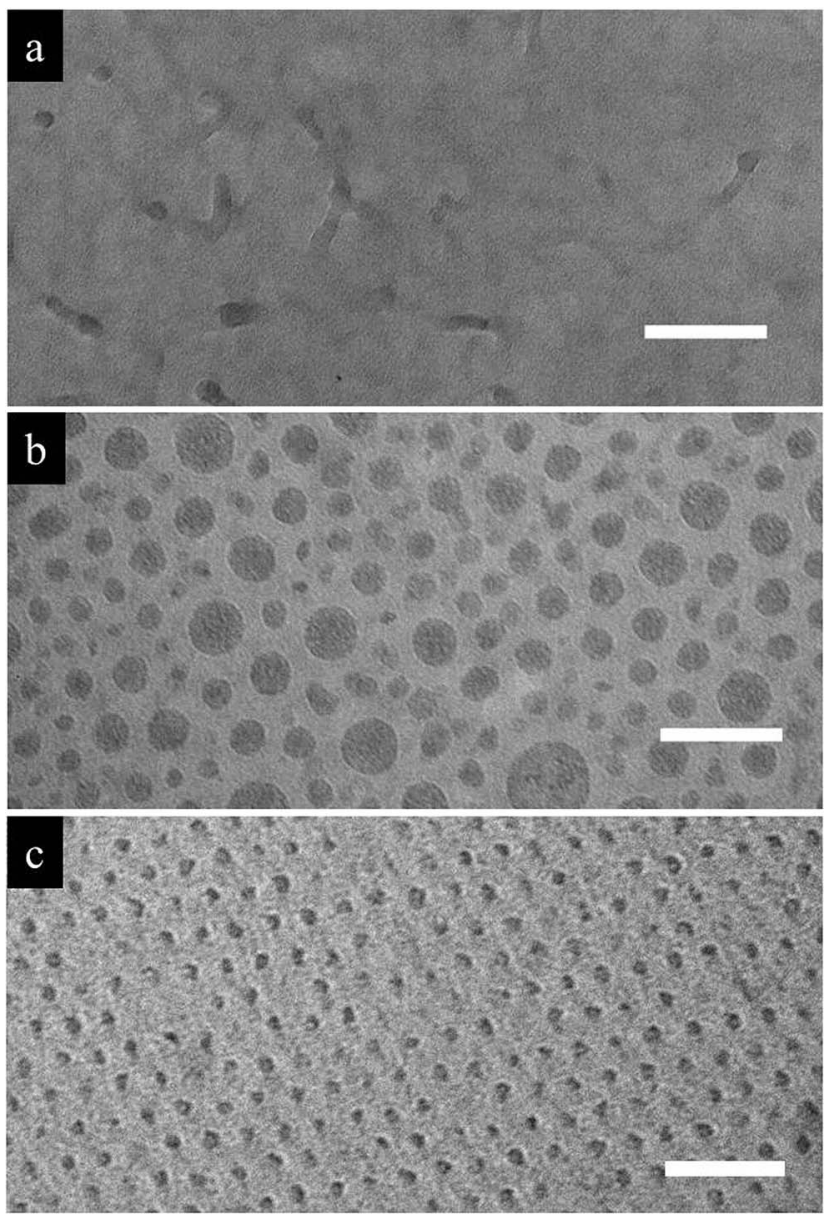

Fig. 2 Transmission electron micrograph of (a) EISA (Ti precursor) films after annealing with toluene/water vapor and (b) toluene vapor as compared to a (c) SPICE Ti precursor film. Images are unstained; contrast is afforded by the electron density difference between PEO-titanium complex (dark) and PS (light). The scale bars represent $100 \mathrm{~nm}$.

further validation of our synthesis approach, a toluene solution of gold nanoparticles $(3.5 \pm 1.0 \mathrm{~nm}$ diameter $)$ was spincoated onto SPICE- and EISA-templated $\mathrm{TiO}_{2}$. The resulting $\mathrm{Au} / \mathrm{TiO}_{2}$ catalysts contained approximately $5 \mathrm{~mol} \% \mathrm{Au}$ as determined by XPS survey scans (not shown). SPICE-templated $\mathrm{TiO}_{2}$ arrays maintained their high degree of ordering and dispersity after $\mathrm{Au}$ addition (Fig. 1e).

Photocatalytic studies were used to demonstrate the increased activity of SPICE $\mathrm{TiO}_{2}$ compared to EISA $\mathrm{TiO}_{2}$. Aqueous solutions of $\mathrm{MB}$ were photocatalyzed, under irradiation, with EISA $\mathrm{TiO}_{2}$, SPICE $\mathrm{TiO}_{2}$, and SPICE-templated and EISA-templated $\mathrm{TiO}_{2}$ coated with gold nanoparticles (Fig. 3). Cuvettes with no catalyst (Blank) and MB stored in the dark (Dark) were used as controls. More specifically, the Blank cuvette indicates how much MB degradation occurs due to irradiation alone. UV-vis spectra were collected every two hours, and peak areas were integrated between 550-740 nm (Fig. S2 $\dagger$ ). MB photodegradation was presumed to follow first order kinetics as indicated by the following expression: ${ }^{20}$ 


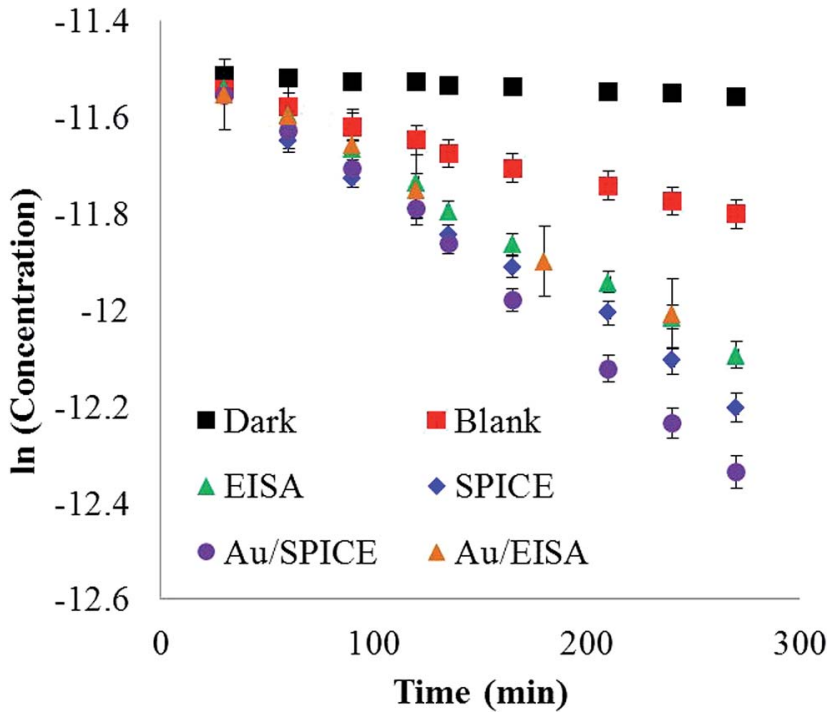

Fig. 3 Plot of the natural log of MB concentrations against irradiation time. Error bars on data points represent standard deviations of the mean across three reproducibility studies. The slopes represent rate constants $(k)$, which are reported in Table 1 . The value of $k_{\text {Dark }}$ was taken to be the error in the rate constants.

$$
\frac{-\mathrm{d}[\mathrm{MB}]}{\mathrm{d} t}=k[\mathrm{MB}] .
$$

The first order rate constants $(k)$ were determined by fitting linear regressions of the $\mathrm{MB}$ concentrations as a function of irradiation time as shown in Fig. 3. The reaction rate constants followed $k_{\mathrm{Au} / \mathrm{SPICE}}>k_{\mathrm{SPICE}}>k_{\mathrm{Au} / \mathrm{EISA}}=k_{\mathrm{EISA}}>k_{\mathrm{Blank}}>k_{\text {Dark }}$ and are listed in Table 1.

The value of $k_{\text {Dark }}$ was attributed to instrumental drift and was used as the error associated with the rate constants. SPICE $\mathrm{TiO}_{2}$ showed a $13 \%$ increase in photocatalytic activity over EISA $\mathrm{TiO}_{2}$ during $\mathrm{MB}$ degradation experiments. The addition of AuNPs to the SPICE $\mathrm{TiO}_{2}$ samples $\left(\mathrm{Au} / \mathrm{TiO}_{2}\right)$ further improved the photocatalytic activity by $43 \%$. AuNPs did not improve the catalytic activity of the EISA $\mathrm{TiO}_{2}$.

Photocatalytic activity has been shown to depend on catalyst crystallinity, surface hydroxyl concentration, and surface area. ${ }^{63}$ Because the EISA and SPICE methods share the same materials and polymer removal process, it is expected that crystallinity and surface hydroxyl groups remain similar. Both SPICE and

Table 1 Photocatalytic conditions and rate constants

\begin{tabular}{llll}
\hline Sample & Light & Catalyst & Rate constant ${ }^{a}\left(\times 10^{3} \mathrm{~min}^{-1}\right)$ \\
\hline Dark & No & N/A & 0.2 \\
Blank & Yes & N/A & 1.1 \\
EISA & Yes & $\mathrm{TiO}_{2}$ & 2.3 \\
Au/EISA & Yes & ${\mathrm{Au} / \mathrm{TiO}_{2}}_{2}$ & 2.3 \\
SPICE & Yes & $\mathrm{TiO}_{2}$ & 2.6 \\
$\mathrm{Au} /$ SPICE & Yes & $\mathrm{Au} / \mathrm{TiO}_{2}$ & 3.3
\end{tabular}

${ }^{a}$ Error values for the rate constants are given by the magnitude of the Dark rate constant.
EISA processes were carried out at room temperature except for the UVO treatment, which remained below $60^{\circ} \mathrm{C}$. Therefore, the anatase phase is expected for both synthetic processes. ${ }^{64}$ The improvement in photocatalytic efficiency was attributed to increased surface area, as the SPICE-templated $\mathrm{TiO}_{2}$ surface area was increased by minimizing the $\mathrm{TiO}_{2}$ size distribution (Fig. S3†). Exposed surface area was estimated to be $25 \%$ larger for SPICE $\mathrm{TiO}_{2}$ over EISA $\mathrm{TiO}_{2}$; uncertainty in the measurement stems from the variations in EISA dot sizes. In addition to an improvement over EISA $\mathrm{TiO}_{2}$, our experiments demonstrated a $27 \%$ activity gain between SPICE $\mathrm{Au} / \mathrm{TiO}_{2}$ over SPICE $\mathrm{TiO}_{2}$. On the other hand, our EISA $\mathrm{Au} / \mathrm{TiO}_{2}$ exhibited no improvement over EISA $\mathrm{TiO}_{2}$. Numerous previous studies have demonstrated improvements to EISA $\mathrm{TiO}_{2}$ photocatalysts by adding metal nanoparticles. Catalysts were optimized by changes in synthetic techniques and metal type and loading. In some cases, AuNP addition caused losses in photocatalytic activity. ${ }^{60,65}$ Amongst our experiments, the simple addition of AuNPs to EISA $\mathrm{TiO}_{2}$ yielded no change, which indicated that optimization is required. On the other hand, AuNPs that were simply spincoated onto the SPICE $\mathrm{TiO}_{2}$ yielded an improvement of $27 \%$. The improvement in efficiency indicates that the SPICE $\mathrm{TiO}_{2}$ can be more easily optimized and augmented than EISA $\mathrm{TiO}_{2} \cdot{ }^{61,62}$

\section{Conclusions}

In conclusion, the SPICE templating method (spincoat-patternimmersion-complex-etch) was used to produce arrays of a variety of metal oxides. The method decoupled metal-PEO complexation from BCP ordering and thus enabled both exceptionally well-ordered arrays and simple sol-gel templating. A variety of metal oxides were templated; all exhibited the same high degree of ordering as their sacrificial BCP thin film template. In particular, $\mathrm{TiO}_{2}$ arrays exhibited a high degree of ordering and narrow size dispersion, which could not be achieved using standard EISA methods. Finally, MB photodegradation studies showed that the SPICE $\mathrm{TiO}_{2}$ (1) showed a $13 \%$ increase in photocatalytic activity over EISA $\mathrm{TiO}_{2}$ and (2) could be augmented easily with gold nanoparticles to further improve photocatalytic activity by $27 \%$, whereas the EISA Au/ $\mathrm{TiO}_{2}$ showed no such improvements. The SPICE method opens exciting pathways for thin films of ordered metal oxides in sensors, magnetic bit storage media, and energy harvesting.

\section{Acknowledgements}

This work was partially supported by the National Science Foundation (NSF) through DMR-1207041 to T.H.E. and the South Carolina SmartState ${ }^{\mathrm{TM}}$ center for Strategic Approaches to the Generation of Electricity (SAGE). M.K.M. thanks the NSF Solar Hydrogen IGERT Program (no. DGE-0549399) for funding. J.H. acknowledges the Global Research Collaboration Program of Semiconductor Research Corporation (Task ID 2222.001). We acknowledge Prof. Chuanbing Tang for use of the atomic force microscope and Prof. Miao Yu for use of the solar simulator. 


\section{References}

1 G. J. d. A. A. Soler-Illia, C. Sanchez, B. Lebeau and J. Patarin, Chem. Rev., 2002, 102, 4093-4138.

2 C. J. Brinker, MRS Bull., 2004, 29, 631-640.

3 F. S. Bates, M. A. Hillmyer, T. P. Lodge, C. M. Bates, K. T. Delaney and G. H. Fredrickson, Science, 2012, 336, 434-440.

4 F. S. Bates and G. H. Fredrickson, Phys. Today, 1999, 52, 3238.

5 M. Rawolle, M. A. Niedermeier, G. Kaune, J. Perlich, P. Lellig, M. Memesa, Y. J. Cheng, J. S. Gutmann and P. MullerBuschbaum, Chem. Soc. Rev., 2012, 41, 5131-5142.

6 K. Koo, H. Ahn, S.-W. Kim, D. Y. Ryu and T. P. Russell, Soft Matter, 2013, 9, 9059-9071.

7 C. Sinturel, M. Vayer, M. Morris and M. A. Hillmyer, Macromolecules, 2013, 46, 5399-5415.

8 M. Luo and T. H. Epps III, Macromolecules, 2013, 46, 75677579.

9 J. N. L. Albert, W. S. Young, R. L. Lewis, T. D. Bogart, J. R. Smith and T. H. Epps III, ACS Nano, 2012, 6, 459-466.

10 J. E. Seppala, R. L. Lewis and T. H. Epps III, ACS Nano, 2012, 6, 9855-9862.

11 R. A. Segalman, Mater. Sci. Eng., R, 2005, 48, 191-226.

12 C. Park, J. Yoon and E. L. Thomas, Polymer, 2003, 44, 67256760.

13 C. M. Bates, M. J. Maher, D. W. Janes, C. J. Ellison and C. G. Willson, Macromolecules, 2014, 47, 2-12.

14 D. J. C. Herr, J. Mater. Res., 2011, 26, 122-139.

15 D. E. Angelescu, J. H. Waller, D. H. Adamson, P. Deshpande, S. Y. Chou, R. A. Register and P. M. Chaikin, Adv. Mater., 2004, 16, 1736-1740.

16 S. O. Kim, H. H. Solak, M. P. Stoykovich, N. J. Ferrier, J. J. de Pablo and P. F. Nealey, Nature, 2003, 424, 411-414.

17 X. Quan, S. Yang, X. Ruan and H. Zhao, Environ. Sci. Technol., 2005, 39, 3770-3775.

18 H. F. Zhuang, C. J. Lin, Y. K. Lai, L. Sun and J. Li, Environ. Sci. Technol., 2007, 41, 4735-4740.

19 Y. Li, T. Sasaki, Y. Shimizu and N. Koshizaki, J. Am. Chem. Soc., 2008, 130, 14755-14762.

20 A. Houas, H. Lachheb, M. Ksibi, E. Elaloui, C. Guillard and J.-M. Herrmann, Appl. Catal., B, 2001, 31, 145-157.

21 A. Syoufian and K. Nakashima, J. Colloid Interface Sci., 2008, 317, 507-512.

22 H. Acharya, J. Sung, I. Bae, T. Kim, D. H. Kim and C. Park, Chem.-Eur. J., 2012, 18, 14695-14701.

23 M. C. Daniel and D. Astruc, Chem. Rev., 2004, 104, 293-346.

24 M. K. Mayeda, W.-F. Kuan, W.-S. Young, J. A. Lauterbach and T. H. Epps III, Chem. Mater., 2012, 24, 2627-2634.

25 B. J. Kim, J. Bang, C. J. Hawker, J. J. Chiu, D. J. Pine, S. G. Jang, S.-M. Yang and E. J. Kramer, Langmuir, 2007, 23, 12693-12703.

26 B. J. Kim, G. H. Fredrickson and E. J. Kramer, Macromolecules, 2007, 41, 436-447.

27 J. J. Chiu, B. J. Kim, E. J. Kramer and D. J. Pine, J. Am. Chem. Soc., 2005, 127, 5036-5037.
28 B. J. Kim, J. J. Chiu, G. R. Yi, D. J. Pine and E. J. Kramer, Adv. Mater., 2005, 17, 2618-2622.

29 A. C. Balazs, T. Emrick and T. P. Russell, Science, 2006, 314, 1107-1110.

30 A. Haryono and W. H. Binder, Small, 2006, 2, 600-611.

31 M. R. Bockstaller, R. A. Mickiewicz and E. L. Thomas, Adv. Mater., 2005, 17, 1331-1349.

32 J. Kao, K. Thorkelsson, P. Bai, B. J. Rancatore and T. Xu, Chem. Soc. Rev., 2013, 42, 2654-2678.

33 Z. C. Sun, D. H. Kim, M. Wolkenhauer, G. G. Bumbu, W. Knoll and J. S. Gutmann, ChemPhysChem, 2006, 7, 370378.

34 M. C. Orilall and U. Wiesner, Chem. Soc. Rev., 2011, 40, 520535.

35 E. Ortel, A. Fischer, L. Chuenchom, J. Polte, F. Emmerling, B. Smarsly and R. Kraehnert, Small, 2012, 8, 298-309.

36 V. N. Urade, L. Bollmann, J. D. Kowalski, M. P. Tate and H. W. Hillhouse, Langmuir, 2007, 23, 4268-4278.

37 Y. J. Cheng and J. S. Gutmann, J. Am. Chem. Soc., 2006, 128, 4658-4674.

38 D. Grosso, J. Mater. Chem., 2011, 21, 17033-17038.

39 G. Kastle, H. G. Boyen, F. Weigl, G. Lengl, T. Herzog, P. Ziemann, S. Riethmuller, O. Mayer, C. Hartmann, J. P. Spatz, M. Moller, M. Ozawa, F. Banhart, M. G. Garnier and P. Oelhafen, Adv. Funct. Mater., 2003, 13, 853-861.

40 H. G. Boyen, G. Kastle, K. Zurn, T. Herzog, F. Weigl, P. Ziemann, O. Mayer, C. Jerome, M. Moller, J. P. Spatz, M. G. Garnier and P. Oelhafen, Adv. Funct. Mater., 2003, 13, 359-364.

41 J. Polleux, M. Rasp, I. Louban, N. Plath, A. Feldhoff and J. P. Spatz, ACS Nano, 2011, 5, 6355-6364.

42 J. P. Spatz, S. Mossmer, C. Hartmann, M. Moller, T. Herzog, M. Krieger, H. G. Boyen, P. Ziemann and B. Kabius, Langmuir, 2000, 16, 407-415.

43 R. E. Palmer, S. Pratontep and H. G. Boyen, Nat. Mater., 2003, 2, 443-448.

44 D. H. Lee, S. H. Han, W. Joo, J. K. Kim and J. Huh, Macromolecules, 2008, 41, 2577-2583.

45 L. Shan, S. Punniyakoti, M. J. Van Bael, K. Temst, M. K. Van Bael, X. Ke, S. Bals, G. Van Tendeloo, M. D'Olieslaeger, P. Wagner, K. Haenen and H.-G. Boyen, J. Mater. Chem. C, 2014, 2, 701-707.

46 P. A. Mistark, S. Park, S. E. Yalcin, D. H. Lee, O. Yavuzcetin, M. T. Tuominen, T. P. Russell and M. Achermann, ACS Nano, 2009, 3, 3987-3992.

47 T. Ghoshal, T. Maity, J. F. Godsell, S. Roy and M. A. Morris, Adv. Mater., 2012, 24, 2390-2397.

48 T. Ghoshal, T. Maity, R. Senthamaraikannan, M. T. Shaw, P. Carolan, J. D. Holmes, S. Roy and M. A. Morris, Sci. Rep., 2013, 3, 1-8.

49 J. Varghese, T. Ghoshal, N. Deepak, C. O’Regan, R. W. Whatmore, M. A. Morris and J. D. Holmes, Chem. Mater., 2013, 25, 1458-1463.

50 (a) H. Cho, H. Park, T. P. Russell and S. Park, J. Mater. Chem., 2010, 20, 5047-5051; (b) L. L. Wu, B. Leng and A. Bisht, Appl. Phys. A, 2014, 116, 893-900; (c) J. Q. Lu, J. Phys. Chem. C, 2008, 112, 10344-10351; (d) T. Ghoshal, M. T. Shaw, 
C. T. Bolger, J. D. Holmes and M. A. Morris, J. Mater. Chem., 2012, 22, 12083-12089; (e) M. Roulet, M. Vayer and C. Sinturel, Eur. Polym. J., 2013, 49, 3897-3903.

51 S. H. Kim, M. J. Misner, T. Xu, M. Kimura and T. P. Russell, Adv. Mater., 2004, 16, 226-231.

52 M. Brust, M. Walker, D. Bethell, D. J. Schiffrin and R. Whyman, J. Chem. Soc., Chem. Commun., 1994, 801-802.

53 T. H. Epps III, D. M. DeLongchamp, M. J. Fasolka, D. A. Fischer and E. L. Jablonski, Langmuir, 2007, 23, 3355-3362.

54 M. Rawolle, M. A. Ruderer, S. M. Prams, Q. Zhong, D. Magerl, J. Perlich, S. V. Roth, P. Lellig, J. S. Gutmann and P. MullerBuschbaum, Small, 2011, 7, 884-891.

55 B. D. Terris and T. Thomson, J. Phys. D: Appl. Phys., 2005, 38, R199-R222.

56 K. Q. Peng and S. T. Lee, Adv. Mater., 2011, 23, 198-215.

57 NIST X-ray Photoelectron Spectroscopy Database, Version 4.1, National Institute of Standards and Technology, Gaithersburg, 2012, http://srdata.nist.gov/xps/.
58 P. Yang, D. Zhao, D. I. Margolese, B. F. Chmelka and G. D. Stucky, Chem. Mater., 1999, 11, 2813-2826.

59 J. Peng, X. Li, D. H. Kim and W. Knoll, Macromol. Rapid Commun., 2007, 28, 2055-2061.

60 I. M. Arabatzis, T. Stergiopoulos, D. Andreeva, S. Kitova, S. G. Neophytides and P. Falaras, J. Catal., 2003, 220, 127135.

61 A. Primo, A. Corma and H. Garcia, Phys. Chem. Chem. Phys., 2011, 13, 886-910.

62 E. Kowalska, O. O. P. Mahaney, R. Abe and B. Ohtani, Phys. Chem. Chem. Phys., 2010, 12, 2344-2355.

63 K. Nagaveni, G. Sivalingam, M. S. Hegde and G. Madras, Appl. Catal., B, 2004, 48, 83-93.

64 A. A. Gribb and J. F. Banfield, Am. Mineral., 1997, 82, 717728.

65 E. Kowalska, M. Janczarek, L. Rosa, S. Juodkazis and B. Ohtani, Catal. Today, 2014, 230, 131-137. 